\title{
Designing processing and fermentation conditions for long-life set yoghurt for made-in- transit (MIT) product
}

\begin{abstract}
Extending yoghurt fermentations could facilitate yoghurt distribution by allowing the fermentation to occur during transportation - a concept known as "made-in-transit" (MIT). The objective was to determine the starter culture composition, inoculum size and fermentation temperature for extending yoghurt fermentations to $168 \mathrm{~h}$. The yoghurt was processed using a milk base sterilized by ultra-high temperature (UHT) treatment at $138 \mathrm{C}$ for 6 s. Factorial experiments for yoghurt processing were designed with starter culture combinations of STLB (Streptococcus thermophilus with Lactobacillus delbrueckii subsp. bulgaricus) and STLA (S. thermophilus with L. acidophilus), inoculum sizes of 2.0 and $0.2 \%$ $(\mathrm{v} / \mathrm{v})$ and fermentation temperatures of 25 or $35 \mathrm{C}$. The fermentation was monitored over 168 $\mathrm{h}$ using $\mathrm{pH}$, starter culture concentration and firmness. The combination of STLA, and a $0.2 \%$ inoculum, fermented at $25 \mathrm{C}$ extended the yoghurt fermentation to $168 \mathrm{~h}$; however, no gel formed. The best product was produced with a STLB starter combination of $2.0 \%$ inoculum fermented at $35 \mathrm{C}$ for $24 \mathrm{~h}$. This shows the constraints and limitations of applying the MIT concept to a fermented food.
\end{abstract}

Keyword: Yoghurt fermentations; Made-in-transit (MIT) 